\title{
Research on the Influence of Social Media Short Video Marketing on Consumer Brand Attitude
}

\author{
Gao-fu LIU \\ Business school of Jiangxi Normal University \\ Nanchang, China \\ Yu-chun LI \\ Business school of Jiangxi Normal University \\ Nanchang, China
}

\author{
Peng-chao GAO* \\ Business school of Jiangxi Normal University \\ Nanchang, China \\ Zhuo-ping ZHANG \\ Business school of Jiangxi Normal University \\ Nanchang, China
}

\begin{abstract}
In recent years, short video has become the new darling of the Internet after network broadcast by virtue of its characteristics such as short time, high degree of entertainment, easy production and sharing. In this context, how to effectively use social media short video for marketing has become a hot topic in academic circles. This paper will take social media short video as the main research object to explore the impact of enterprises' use of social media short video marketing on consumers' brand attitude. Specifically, this paper divides social media short video marketing into three dimensions: interesting content, scene-based experience and user participation interaction, and constructs a relationship model with short video marketing as an independent variable, brand perception as a mediator variable, and brand attitude as a dependent variable. SPSS24.0 was used to analyze the data collected from 363 questionnaires, and the following conclusions were drawn: interesting content, scene-based experience, and user participation and interaction have a positive impact on brand attitude; Brand perception plays a part of intermediary role between short video marketing and brand attitude. This paper has guided significance for enterprises to use short video marketing to build brand.
\end{abstract}

Keywords-Social Media Short Video Marketing; Consumer Brand Attitude; Brand Perception

\section{INTRODUCTION}

In 2018, with the sustained and rapid development of the short video industry in China, various enterprises have tried to use the short video pan-entertainment content to establish a connection with consumers and cultivate a positive brand attitude. In this context, it is very necessary and important to conduct relevant theoretical research on short video marketing of social media. Unfortunately, most of the current research focuses on the case analysis of short video marketing. Scholars have not put forward the essential elements of marketing with a short video. Few researches divided short video marketing of social media into several dimensions, and did not explore the impact of enterprises' use of short video marketing on brands. Thus, there was no answer: which factors of short video marketing of social media would influence consumers' brand attitude? And what kind of impact does it have?
In order to explore this problem, first of all, this paper USES literature analysis to sort out existing research results on short video marketing of social media and consumer brand attitude, so as to divide short video marketing of social media into three dimensions: interesting content, scene-based experience and user participation and interaction. Moreover, the influence of brand perception on consumers' brand attitude is summarized. Secondly, empirical analysis is used to verify the relevant research. Questionnaire survey and mathematical statistical analysis were mainly adopted to verify the influence of short video marketing on consumers' brand attitude on social media, and the mediating effect of brand perception on short video marketing on social media and consumers' brand attitude.

The theoretical and practical significance of this paper is mainly reflected in the following two aspects. First, this paper divides short video marketing into three dimensions and explores the role of enterprises in the application of short video marketing in practice, which can make up for this gap in academia to a certain extent. Second, this article helps companies or individuals understand what factors influence brand attitudes when developing short video marketing, and provide them with correct theoretical guidance in corporate practice.

\section{LITERATURE REVIEW}

\section{A. Research on short video marketing of social media}

The short video originated from a Vine application released by the United States in 2009. Users can use the software to create videos within ten seconds and share them on social platforms. Since then, short videos have entered people's life. Xiu-qi Li (2017) believes that short video refers to video clips that can be shared, uploaded, and then shared by various digital video terminals [1]. Hu TAO and Jing-hui YANG (2018) believes that short video is a few seconds of video content that is played on a new media platform and is suitable for watching in a short period of leisure. The playing time ranges from a few seconds to a few minutes [2]. It is not difficult to see that scholars are defined by the length of the short video and the medium of support. This paper believes that short video is a new type of video that can be shared, 
forwarded and viewed on social media short video platforms within 3 minutes, mainly using mobile intelligent terminals for shooting and editing.

The reason why short video is widely concerned by scholars is mainly because of its great value to the marketing activities of enterprises. The role of short video is to enhance brand awareness and foster customer brand loyalty by generating brand associations, and then effectively enhance the value of the brand itself [3]. Compared with traditional video, short video is more interactive and interactive, so if you can effectively take advantage of short video marketing, it will promote the establishment and dissemination of the brand [4]. The rise of short video widens the scene when consumers watch video, and makes information interact deeply among consumers, playing an important role in the reconstruction of consumer relations [5].

\section{B. Research on consumer brand attitude}

Consumer brand attitude is an important research topic in consumer behavior. Accurately grasping consumers' attitudes towards their own brands helps companies to tap the needs of consumers. Fishbein and Ajzen (1975) believed that brand attitude is the preference or aversion of consumers towards a certain brand [6]. Percy and Rossiter (1992) define it as a comprehensive evaluation of a brand's ability to meet its needs and goals. Jun-wu CHAI (2007) pointed out that consumer brand attitude is the consumer's perception and emotion of the overall quality of the brand. Xiao-hong Hu (2009) considers it to be an overall assessment of a brand by consumers. To sum up, this paper holds that brand attitude refers to the habitual tendency of consumers to like or dislike a brand acquired through learning and strengthening.

It is generally believed that brand attitude consists of three dimensions: cognition, emotion and behavioral intention. Scholars have analyzed the relationship between these three dimensions. Kleingiima believes that the occurrence of cognition and emotion is synchronous and asynchronous. Aas and Bjns believe that specific emotions and behavioral intentions are triggered by certain cognition, and positive perceptions generally believe that positive emotions produce positive emotions [7]. Jong Wo oJun's research shows that consumer perception first directly affects consumer emotions and then indirectly affects consumer behavioral intentions.

\section{Brand perception research}

Brand perception is the feeling and perception of consumers using sensory organs on the brand image, brand culture and brand value, which reflects the overall impression of the brand in the consumer's brain. In the early days, scholars studied brand perception through a single element such as brand image and brand reputation. Among them, brand perceived quality has been studied several times. Subsequently, the academic research direction of brand perception gradually diversified, including the perception of the brand's natural attributes, social attributes, emotional attributes and other aspects. Aaker (2004) proposed that consumers pay attention to their brand perception and brand sentiment in addition to the quality and characteristics of the brand [8].

\section{RESEARCH MODEL AND RESEARCH HYPOTHESIS}

According to the review and research of the previous literature, the author proposes the empirical model of this paper. As shown in Fig. 1:

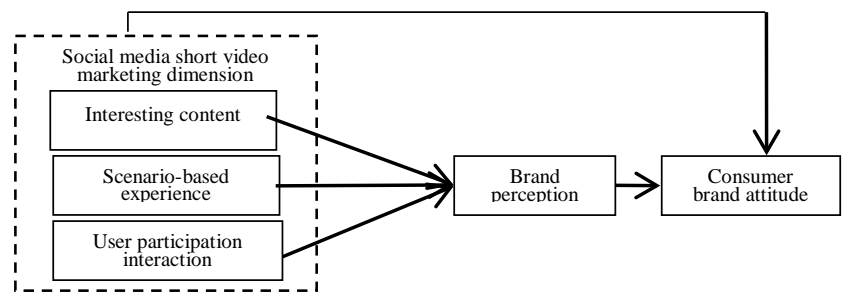

Fig. 1. Research model

\section{LITERATURE REVIEW}

\section{A. Interesting content and brand attitude}

In essence, the essence of short video marketing is content marketing. Sally (2003) once pointed out that the interestingness of marketing content can arouse consumers' willingness to spread and share more than other characteristics, and the interestingness of content promotes consumers to have a positive image of the brand, and thus to have a positive attitude towards the brand [9]. Chen and Rodgers (2008) believe that the so-called interestingness is the content that can attract consumers and arouse people's curiosity, while entertaining and interesting content can make people more easily accept the content conveyed. Rose R (2013) believes that the key to a good effect of content marketing is that the information it conveys must be useful and interesting. If neither of them is satisfied, the expected marketing effect will be difficult to achieve [10]. Therefore, the following hypothesis is proposed:

H1a: short video interesting content has a significant positive effect on brand attitude

\section{B. Scene-based experience and brand attitude}

At present, when content and content are highly fragmented, consumers' needs and choices are highly personalized, and their behavior and psychology are greatly affected by the scene. Short video marketing often builds real-life consumption scenarios for consumers in advance, organically integrates consumers and brands, and helps consumers estimate brand value and consumer experience. Chang-xiao WANG believes that mobile media video is a kind of "scene media", which can provide more and more accurate information, and the scene information is easier to be accepted and understood by people [9]. Therefore, the hypothesis is proposed:

H1b: The scene-based experience of short video has a significant positive effect on brand attitude

\section{User participation interaction and brand attitude}

Communication scholar Denis mcquail has pointed out that in the new media era, active questioners, responders and communicators will replace passive listeners, consumers and target users in the traditional media era. It can be seen that in the era of the Internet of everything, people are no longer satisfied with passive acceptance of information, but are more 
willing to participate in the production and dissemination of information. Short videos just cater to people's needs. Yu DONG (2011) once pointed out that the degree of interaction between brands and consumers significantly affects consumers' cognitive and emotional attitudes towards specific brands, and the higher the degree of interaction, the easier it is to form a positive brand attitude [11]. Xing YAN and Ya-ping CHANG (2013) believes that if users often communicate actively with brands, users will easily form a strong relationship, and they will be more likely to believe in the information sent by each other [12]. Therefore, the hypothesis is proposed:

H1c: user participation interaction has a significant positive effect on brand attitude

\section{Mediating effect of brand perception}

In brand practice, brand perception is intangible. Consumers' perception of a brand is to first use its sensory organs, perceive a brand's brand image, brand culture and brand value, and then form an overall impression of the brand. The way brands are transmitted has a profound impact on consumers' perception of the brand. Brand perception is the foundation for consumers to recognize and understand brands. Sirgy (1982) pointed out that when consumers are aware of the brand, if they can make them feel satisfied with the brand, they will stimulate consumers' positive attitude towards the brand [13]. Aaker (1996) argues that consumer perceptions of brands can affect their brand-related stimuli [14]. Therefore, the hypothesis is proposed:

H2a: Brand perception plays an intermediary role in the influence of interesting content on brand attitude.

H2b: Brand perception plays an intermediary role in the influence of scene-based experience on brand attitude.

H2c: Brand perception plays an intermediary role in the influence of user participation interaction on brand attitude.

\section{RESEARCH DESIGN AND EMPIRICAL ANALYSIS}

\section{A. Variable definitions}

According to the previous analysis, there are 5 variables in this paper. $\mathrm{T}$ The specific definition of each variable is as follows:

- Interesting Content: it refers to the novelty, entertainment, fun and uniqueness of the content, which can stimulate consumers to generate strong interest and curiosity, so that they can create a fascinating connection to the brand.

- Scenario-Based Experience: Using short videos to create different consumer and life scenarios for consumers, organically integrate the environment of consumers, products, services and brands to help consumers estimate brand value and consumer experience in specific consumption scenarios.

- User Participation Interaction: The degree to which users participate in the production of short video content, establish interpersonal relationships among different users, communicate and exchange brand related information, and obtain emotional support and trust. This includes the interactive behavior of searching for information, obtaining information and publishing information.

- $\quad$ Brand Perception: It refers to the habitual tendency of consumers to react to a brand in a way of liking or not, which is acquired through learning and strengthening. It is mainly manifested in the overall evaluation of a brand by consumers. It consists of three dimensions: cognition, emotion and behavior.

- Consumer Brand Attitude: he overall impression of the brand in the minds of consumers, the consumer's perception and perception of a brand on the short video platform of social media is the consumer's overall perception of all aspects of the information elements of the brand.

\section{B. Research design}

First of all, the Likert five-point rating scale was used in this study, including social media short video marketing scale, brand perception scale and brand attitude scale. This part of the scale design is divided into two steps: first, through a large number of literature review and interviews to get the scale questions; Second, preliminary investigation, the purpose is to improve the reliability and validity of questionnaire, to further adjust and improve the multi-item and eventually form a formal questionnaire, the questionnaire is divided into two parts, the first part is the main content of the questionnaire (including social media short video marketing three dimension scale, brand perception scale and brand attitude scale), the second part is the investigation object of personal information (including gender, age, and watch a short video of time).Secondly, formal questionnaire survey is carried out. Finally, the collected data is collated and analyzed. After obtaining the survey data, the paper explores the relationship between the three dimensions of social media short video marketing, brand perception and consumer brand attitude through quantitative research on the sampled data.

\section{Sample characteristics}

This survey is mainly conducted by means of questionnaire survey and randomly distributed online. Mainly using the questionnaire survey website, the questionnaire was published on the Internet, and randomly invited consumers to accept the survey through E-mail, QQ group and other channels. A total of 363 questionnaires were collected. Due to the use of some technical design, all the collected questionnaires are valid. Later, SPSS24.0 was used to analyze the original data.

TABLE I. SAMPLE STRUCTURE DESCRIPTION

\begin{tabular}{|c|c|c|c|}
\hline Category & Options & Number & Proportion[\%] \\
\hline \multirow{2}{*}{ Gender } & male & 148 & 40.77 \\
\cline { 2 - 4 } & female & 215 & 59.23 \\
\hline \multirow{5}{*}{ Age } & $<\mathbf{1 8}$, & 3 & 0.83 \\
\cline { 2 - 4 } & $\mathbf{1 8} \sim \mathbf{2 5}$ & 234 & 64.46 \\
\cline { 2 - 4 } & $\mathbf{2 6} \sim \mathbf{3 0}$ & 58 & 15.98 \\
\cline { 2 - 4 } & $\mathbf{3 1} \sim \mathbf{4 0}$ & 48 & 13.22 \\
\cline { 2 - 4 } & $\mathbf{4 1} \sim \mathbf{5 0}$ & 8 & 2.2 \\
\cline { 2 - 5 } & $\mathbf{3 0}$ & 1 & 0.28 \\
\hline
\end{tabular}




\begin{tabular}{|c|c|c|c|}
\hline \multicolumn{4}{|c|}{ Con.t to TABLE I } \\
\hline \multirow{4}{*}{$\begin{array}{c}\text { Watch short video } \\
\text { duration/day }\end{array}$} & $<\mathbf{1 ~ h}$ & 179 & 49.31 \\
\cline { 2 - 5 } & $\mathbf{1} \sim \mathbf{2 ~ h}$ & 132 & 36.36 \\
\cline { 2 - 5 } & $\begin{array}{c}\mathbf{2 . 1} \sim \mathbf{3} \\
\mathbf{h}\end{array}$ & 38 & 10.47 \\
\cline { 2 - 4 } & $\mathbf{>} \mathbf{~ h}$ & 14 & 3.86 \\
\hline
\end{tabular}

In this survey, men account for $40.61 \%$ and women for $59.39 \%$, which is in line with the actual feature that more women watch short video than men. The proportion of 18-25 years old is $64.36 \%$, accounting for the main part, $16.02 \%$ of 26-30 years old and $13.26 \%$ of $31-40$ years old. The survey objects in this paper are mainly those who often watch short video, and most of them are young people, which is in line with the characteristics of short video getting younger. Less than 1 hour accounted for $49.17 \%, 1-2$ hours accounted for $36.46 \%$, 2-3 hours accounted for $10.5 \%$, which is consistent with the short video length, fragmentation characteristics, people often use fragmentary time to watch. To sum up, the survey data are representative.

D. Reliability and validity analysis

TABLE II. RELIABILITY AND VALIDITY ANALYSIS

\begin{tabular}{|c|c|c|}
\hline Variables & Measurement question & Factor load \\
\hline \multirow{4}{*}{$\begin{array}{c}\text { Interesting content } \\
\alpha=.816 \\
\mathrm{KMO}=.759\end{array}$} & I'm always attracted to the short video which is full of fun & .762 \\
\hline & I often watch a short video several times because it is so interesting & .825 \\
\hline & I can often think of short video's that are more interesting & .603 \\
\hline & I am more receptive to short video content that is more interesting & .685 \\
\hline \multirow{4}{*}{$\begin{array}{c}\text { Scenario-based experience } \\
\alpha=.748 \\
\mathrm{KMO}=.641\end{array}$} & Short video in a lot of consumption scenarios I feel very real and appropriate & .692 \\
\hline & Many of the life scenes in short video made me feel like I was there & .619 \\
\hline & Many of the consumption scenarios in short video enhance the expected consumption experience & .626 \\
\hline & The consumption scenario in short video made me have a series of associations & .702 \\
\hline \multirow{4}{*}{$\begin{array}{c}\text { User participation interaction } \\
\qquad \begin{array}{c}\alpha=.735 \\
\mathrm{KMO}=.728\end{array}\end{array}$} & I often thumb up, comment on short video, and enjoy making and sharing & .853 \\
\hline & In interacting with others, I feel real and easy to reach consensus & .746 \\
\hline & I like to get information and improve my cognition through interaction with others & .721 \\
\hline & When communicating with others, I tend to believe the majority's opinion & .615 \\
\hline \multirow{5}{*}{$\begin{array}{c}\text { Brand perception } \\
\alpha=.734 \\
\mathrm{KMO}=.708\end{array}$} & I can feel the image of a brand through short video & .548 \\
\hline & I can feel the grade and quality of the brand from short video & .751 \\
\hline & Short video can enrich my understanding of some brands & .685 \\
\hline & The brand information conveyed by short video can stimulate my thinking & .582 \\
\hline & I am often impressed by the brand content conveyed in short video & .635 \\
\hline \multirow{5}{*}{$\begin{array}{c}\text { Consumer brand attitude } \\
\alpha=.822 \\
\mathrm{KMO}=.737\end{array}$} & By watching short videos, I remembered some brands & .792 \\
\hline & By watching short videos, I have a new understanding of some brands. & .818 \\
\hline & By watching a short video, I have a positive feeling for a brand. & .857 \\
\hline & By watching a short video, it provoked my impulse to buy a brand. & .786 \\
\hline & I often introduce brands that I know through short videos to my friends and family. & .759 \\
\hline
\end{tabular}

Cronbach's alpha coefficient was used to test the reliability of the questionnaire. The overall alpha value of the questionnaire was 0.807 , indicating that the scale used in the questionnaire was of good reliability and high reliability. The alpha value of all the five variables was above 0.7 , which was in line with the standards set in this study, indicating that the questionnaire was effective.

The validity of the questionnaire mainly includes content validity and structural validity. For content validity, the scales of this study were designed in combination with previous research, and after a small-scale pre-survey, repeated refinement and modification, it is considered to have high content validity. This paper mainly makes structural validity analysis. Before the factor analysis, it is necessary to use the $\mathrm{KMO}$ value for the determination. It is generally considered that the KMO value can be factored above 0.6. From TABLE II, the KMO values of all variables are above 0.6, and factor analysis can be performed. It is generally believed that when the factor load is greater than 0.4, the questionnaire is considered to be valid. In TABLE II, the factor load of each item is greater than 0.4 , so the questionnaire question of this study is valid, and thus the structural validity of the questionnaire is no problem.

\section{E. Correlation analysis}

Person correlation coefficient method is mainly adopted in this study. According to TABLE III, the three dimensions of short video marketing on social media are significantly correlated with brand attitude, with correlation coefficients of $0.538,0.412$ and 0.632 respectively, indicating that short video marketing can affect brand attitude. There is also a significant correlation between short video marketing and brand perception, with correlation coefficients of $0.484,0.496$ and 0.612, respectively. Among them, brand perception has a higher correlation with user participation and interaction. Brand perception is also significantly correlated with brand attitude, with a correlation coefficient of 0.678 . Through the correlation analysis, the relationship between the three dimensions of social media short video marketing and brand attitude, and the relationship between short video marketing and brand perception of social media are preliminarily explained. It is generally believed that if the Person coefficient is greater than 0.75 , there is likely to be collinearity between 
variables. As shown in TABLE III, there is no collinearity between variables in this study.

TABLE III. CORRELATION ANALYSIS

\begin{tabular}{|c|c|c|c|c|}
\hline Variables & $\mathbf{1}$ & $\mathbf{2}$ & $\mathbf{3}$ & $\mathbf{4}$ \\
\hline Interesting content & 1 & & & \\
\hline Scenario-based experience & $.528^{*}$ & 1 & & \\
\hline User participation interaction & .198 & $.259^{* *}$ & 1 & \\
\hline Brand perception & $.484^{* *}$ & $.496^{*}$ & $.612^{* *}$ & 1 \\
\hline Consumer brand attitude & $.538^{* *}$ & $.412^{*}$ & $.632^{*}$ & $.678^{* *}$ \\
\hline
\end{tabular}

**Significant correlation at the 0.01 level (both sides). *.Significantly correlated at 0.05 level (two sides)

\section{CONCLUSION}

\section{A. Main effect test}

TABLE IV. SOCIAL MEDIA SHORT VIDEO MARKETING AND BRAND ATTITUDE REGRESSION ANALYSIS

\begin{tabular}{|c|c|c|c|c|c|}
\hline \multirow{2}{*}{ Model } & \multicolumn{2}{|c|}{$\begin{array}{c}\text { Non-standar } \\
\text { dized } \\
\text { coefficient }\end{array}$} & $\begin{array}{c}\text { Standardiz } \\
\text { ation } \\
\text { coefficient }\end{array}$ & \multicolumn{2}{|c|}{$\begin{array}{c}\text { Collinear } \\
\text { statistic }\end{array}$} \\
\cline { 2 - 6 } & $\boldsymbol{B}$ & $\begin{array}{c}\text { Erro } \\
\boldsymbol{r}\end{array}$ & $\boldsymbol{B}$ & $\begin{array}{c}\text { Tolera } \\
\text { nce }\end{array}$ & VIF \\
\hline Constant & .617 & .126 & & & \\
\hline $\begin{array}{c}\text { Interesting } \\
\text { content(A) }\end{array}$ & .488 & .099 & .468 & .352 & 2.841 \\
\hline $\begin{array}{c}\text { Scene-based } \\
\text { experience(B) }\end{array}$ & .256 & .079 & .212 & .352 & 2.841 \\
\hline $\begin{array}{c}\text { Participation } \\
\text { interaction(C) }\end{array}$ & .392 & .089 & .383 & .352 & 2.841 \\
\hline
\end{tabular}

It is known from TABLE IV that the tolerance values of the three independent variables are all greater than 0.1 , and the VIF values are all less than 10 , indicating that there is no collinearity between the three variables. The $\mathrm{B}$ values are positive, and the significance level of the $T$ value is 0.000 , less than 0.01. Therefore, there is a significant positive causal relationship between the three dimensions of the independent variable and the brand attitude. The equation of brand attitude is: $\mathrm{Y}=0.468 \mathrm{~A}+0.212 \mathrm{~B}+0.383 \mathrm{C}+0.617$, and their influence on brand attitude is from strong to weak: $\mathrm{A}>\mathrm{C}>\mathrm{B}$. Therefore, it is assumed that H1a, H1b, and H1c are established.

\section{B. Brand perception intermediary role test}

The so-called mediating effect refers to the independent variable acting on the mediating variable and the mediating variable acting on the dependent variable. The mediating variable ACTS as a bridge connecting the independent variable and the dependent variable. In other words, the intermediate variable is a function of the independent variable, and the dependent variable is a function of the intermediate variable. Mediation variables can be divided into partial mediation and complete mediation. The following research is conducted.
TABLE V. ANALYSIS OF THE MEDIATING ROLE OF BRAND PERCEPTION N INTERESTING CONTENT AND BRAND ATTITUDE

\begin{tabular}{|c|c|c|c|}
\hline Model & $\begin{array}{c}\text { Brand perception } \\
\text { standard coefficient }\end{array}$ & $\begin{array}{c}\text { Brand attitude } \\
\text { standard } \\
\text { coefficient }\end{array}$ & Sig \\
\hline $\begin{array}{c}\text { Interesting } \\
\text { content }\end{array}$ & .704 & .677 & .000 \\
\hline $\begin{array}{c}\text { Interesting } \\
\text { content }\end{array}$ & & & .000 \\
\hline $\begin{array}{c}\text { Interesting } \\
\text { content }\end{array}$ & & .462 & 000 \\
\hline Brand perception & & .314 & 000 \\
\hline
\end{tabular}

TABLE VI. ANALYSIS OF THE MEDIATING ROLE OF BRAND PERCEPTION IN SCENE-BASED EXPERIENCE AND BRAND ATTITUDE

\begin{tabular}{|c|c|c|c|}
\hline Model & $\begin{array}{c}\text { Brand } \\
\text { perception } \\
\text { standard } \\
\text { coefficient }\end{array}$ & $\begin{array}{c}\text { Brand attitude } \\
\text { standard } \\
\text { coefficient }\end{array}$ & Sig \\
\hline Scene-based experience & & .626 & .000 \\
\hline Scene-based experience & .752 & & .000 \\
\hline Scene-based experience & & .428 & 000 \\
\hline Brand perception & & .329 & 000 \\
\hline
\end{tabular}

TABLE VII. ANALYSIS OF THE MEDIATING ROLE OF BRAND PERCEPTION IN USER PARTICIPATION INTERACTION AND BRAND ATTITUDE

\begin{tabular}{|c|c|c|c|}
\hline Model & $\begin{array}{c}\text { Brand } \\
\text { perception } \\
\text { standard } \\
\text { coefficient }\end{array}$ & $\begin{array}{c}\text { Brand attitude } \\
\text { standard } \\
\text { coefficient }\end{array}$ & Sig \\
\hline $\begin{array}{c}\text { User participation } \\
\text { interaction }\end{array}$ & & .663 & .000 \\
\hline $\begin{array}{c}\text { User participation } \\
\text { interaction }\end{array}$ & .699 & & .000 \\
\hline $\begin{array}{c}\text { User participation } \\
\text { interaction }\end{array}$ & & .435 & 000 \\
\hline Brand perception & & .296 & 000 \\
\hline
\end{tabular}

It can be seen from TABLE V, VI and VII that the three dimensions of the independent variables have significant regression coefficients for brand attitudes, and the standard regression coefficients are $0.677,0.626$, and 0.663, respectively. Secondly, the three dimensions of the independent variables have significant regression coefficient standard regression coefficients for the perception of the mediator variables, which are 0.704, 0.752, and 0.699, respectively.

The three dimensions of the independent variable and the brand perception of the intermediate variable are added to the equation at the same time, and multiple regression analysis is performed on the brand attitude of the dependent variable. The results show that the standard regression coefficients of brand perception for brand attitude are 0.314, 0.329, and 0.296, respectively. A significant test was passed $(p<0.01)$. In addition, after adding the brand awareness of mediation variables, the standard regression coefficient of interesting content to brand attitude decreased from 0.677 to 0.462 ; the standard regression coefficient of scene experience to brand attitude decreased from 0.626 to 0.428 ; the standard regression coefficient decreased from 0.663 to 0.435 , indicating that interesting content, scene-based experience, and user participation interaction have a reduced impact on brand attitudes due to the addition of brand perception, and 
indicating that brand perception plays a part of intermediary role between the three dimensions of short video marketing and brand attitude. Therefore, it is assumed that $\mathrm{H} 2 \mathrm{a}, \mathrm{H} 2 \mathrm{~b}$, and H2c are established.

\section{CONCLUSION AND DISCUSSION}

\section{A. Conclusion and suggestion}

Based on the above findings, the following conclusions and recommendations can be obtained from this study:

1) Interesting content has a positive impact on brand attitudes. When enterprises use short video marketing, they should strictly check the content of short video, create short video content with strong interest and high degree of entertainment, integrate the brand culture into the content of extensive entertainment, and enhance consumers' cognition and emotion of the brand in a relaxed and pleasant way.

2) Scene-based experience has a positive impact on brand attitude. When enterprises make use of short video marketing, they can provide consumers with a real scene that can be sensed by themselves through elaborately designed life scenes and consumption scenes, so as to help enterprises display brand image comprehensively and variously and spread brand culture, thus gaining more consumers' recognition.

3) User participation interaction has a positive impact on brand attitude. When enterprises use short video marketing, they should stimulate more users to participate in the creation and imitation of short video, and promote the frequent benign interaction between them, so as to deepen consumers' understanding of the brand and stimulate consumers' positive attitude towards the brand.

4) Brand perception plays a partial intermediary role in the influence of short video marketing on brand attitude. When enterprises use short video marketing, short video should give full consideration to consumers' visual and auditory perception and brand exposure times and ways, and use interesting content and scene-based experience to improve consumers' perception of the brand, so as to promote consumers to have a positive brand attitude.

\section{B. Research innovation}

First, at present, scholars' research on short video marketing of social media focuses on its marketing model, strategy and value, while it is rare to decompose short video marketing into several dimensions for related research. It can be said that it is an innovation.

Second, this paper selects a unique perspective to explore the impact of social media short video marketing on brand attitude. Through the construction of the relationship model, it explores the impact of the three dimensions of social media short video marketing on consumers' brand attitude and the intermediary role of brand perception, which is of great innovation.

\section{Research limitations}

In addition to, there are some limitations in this paper. Since the three dimensions used to measure social media short video marketing are designed and boldly adopted by the author, the dimension selection may not be comprehensive. The intermediary variable only takes brand perception, which may be inaccurate. The question design of the variable may not be optimal. Due to the limitation of personal knowledge level, only the preliminary exploration of the problems studied has been carried out. Many problems have not been involved and there is still much room for improvement.

\section{Research outlook}

1) There are various ways to divide dimensions of short video marketing on social media. In the follow-up research, more comprehensive factors should be investigated and more influencing factors should be added to the research model.

2) The survey method in this paper is too single. In the follow-up study, we will try to add the interviews and other methods to collect the original data expand the scope of the survey, make the relevant data more representatives, and the research results are more authentic.

\section{REFERENCES}

[1] Xiu-qi LI. Short video content guidance and copyright protection system [J]. China Publishing, 2017 (16): 17-21. (In Chinese)

[2] Hu TAO, Jing-hui YANG. On the marketing model of short video [J]. China market, 2018 (32): 119 - 121. (In Chinese)

[3] Wen-sheng, SHAN and Lei LI. Short-term video marketing strategy and value research in the era of mobile internet[J].Journal of Changsha University.2015 29(4):35-37. (In Chinese)

[4] Hao-tian BAI. "seven seconds" marketing -- on short video marketing [J]. News communication, 2016 (3) 48-49. (In Chinese)

[5] Xiao-chun LUO. Innovation and change of short video marketing means [J]. Science and Technology Journal, 2018 (04): 170-171. (In Chinese)

[6] Fishbein, M, Ajzen, I. Belief, Attitude, Intention, and Behavior: An Introduction to Theoiy and Research[M]. Reading, MA; Addision-Wesley. 1975:40

[7] Aas, Bjns. Web-based marketing: The coming revolution in marketing thought and strategy[J].Journal of Business Research, 2004, 57(7):696-702.

[8] Aaker, J. L, Fournier, S. M, Brasel, S. A. When good brands do bad. Journal of Consumer Research, 2004. 31. 1-16

[9] Sally J. Effects of Structural and Perceptual Factors on Attitudes toward the Website[J]. Journal of Advertising Research, 2003, 43 (4): 400-409.

[10] Rose R. Managing Content Marketing - The Real-World Guide for Creating Passionate Subscribers to Your Brand[J]. Sirirajmedj Com, 2013, 2 (1) : 3-19.

[11] $\mathrm{Yu}$ DONG. Research on the influence of traditional media microblog marketing on consumer brand attitude [D]. Jinan University, 2011. (In Chinese)

[12] Xing YAN and Ya-ping CHANG. The Influence of Enterprise Weibo Interactive Strategy on Consumer Brand Relationship[J]. Journal of Marketing Science, 2013(01): 62-78 (In Chinese)

[13] Sirgy, M J. Self-concept in consumer behavior. A critical review .Journal of consumer research , 1982, 9 (3) 287-300

[14] Aaker, D A. Measuring brand equity across products and markets. California Management Review, 1996, 38 (3) , 103 